Postdoc.

Billedkunstskolernes Institut for kunst, skrift og forskning,

Det kongelige danske kunstakademi

\title{
DEN SPALTEDE AFFORTRYLLELSE
}

\section{Et forstudie til analysen af det reaktionæres genkomst i kapitalismens traditionelle arnesteder}

\author{
INDLEDNING - OM OVERGANGEN FRA EN MATERIALISTISKE \\ ERKENDELSESKRITIK TIL EN KRITIK AF ANTIFASCISMEN \\ OG EN IKKE-IDENTIFICERENDE KAPITALKRITIK
}

Hvis man kigger på et politisk kort over USA og Europa, vil man se reaktionens flag blafre: Donald Trumps reality-tv fascisme i USA, Brexit-fiaskoen i Storbritannien, Front Nationals fremmarch i Frankrig, eller AFDs ditto i Tyskland, Dansk Folkepartis erobring af den politiske diskurs i Danmark, Sverigedemokraternes gennembrud, Sebastian Kurzs forlig med Frihedspartiet i Østrig, den nuværende koalition mellem Femstjernebevægelsen og Liga Nord i Italien, Viktor Orbáns Fidesz parti, der regerer i Ungarn, Lov og Retfærdigheds-regeringen i Polen osv. En reaktionær politik har helt tydeligt vind i sejlerne. ${ }^{1}$ Og samtidig er traditionelle demokratiske institutioner ved at miste deres selvfølgelighed, hvilket ofte begrædes, men måske også kan tolkes som tegn på et muligt brud med den brede

1 Cf. Mikkel Bolt, Trumps Kontrarevolution for en analyse af Donald Trumps billedpolitik som en form for underholdningsindustriel neofascisme og de reaktionæres genkomst mere overordnet som en præventiv, kontrarevolutionær løsning på protestbølgen af 2010-11. 
76 KULTUR \& KLASSE $* 126 * 2018$ DET REAKTIONÆRE
77 JAMES DAY

DEN SPALTEDE AFFORTRYLLELSE konsensus om demokratiet som den bedst mulige styrform. Men hvordan kan vi orientere os i dette brud? Hvordan skal vi forstå de forskelligartede politiske former? Er Trumps pop-kulturelle æstetisering af politikken f.eks. kun et skinfænomen af dybtliggende ændringer i kapitalforholdet, eller har værdiens selvforøgelse revet sig løs fra sine politiske støtteformer?

Formålet med nærværende artikel er at situere det reaktionæres genkomst i en analyse af måden, hvorpå det kapitalistiske nationaldemokrati historisk er viklet ind i omlægningen til fascisme (dermed dog ikke sagt, at et fascistisk diktatur ikke kan opstå under andre forhold). ${ }^{2}$ En af de mest interessante analyser af forholdet mellem kapitalforholdet og fascisme findes hos Alfred Sohn-Rethel, hvis analyse af fascismens fremkomst er forankre i et mere omfattende forsøg på at tænke vareformens indre sammenhæng med tankeformer. ${ }^{3}$ Sohn-Rethels kapitalisme kritik blev først udviklet i 1920'erne i kølvandet på den udeblivende tyske revolution og sammenst $\varnothing$ det mellem driftsøkonomien og dannelsen af stormonopoler. I trediverne var Sohn-Rethel gennem sin ansættelse som 'videnskabelig medarbejder' i den Mitteleuropäischer Wirtschaftstag e.V. i den enestående position, at han havde adgang til den tyske kapitalklasses fortrolige overvejelser omkring løsninger for dens tyske økonomis konjunkturkrise, samtidig med at han var en del af en kommunistisk modstandsgruppe. Dermed fik han adgang til informationer om den tyske kapital og dens egen analyse af situationen (Sohn-Rethel, Økonomi og Klassekamp 22), hvilket normalt ikke er tilfældet for systemkritikere.

Efter en indledende gennemgang af Sohn-Rethels fascisme-analyse, fortsætter artiklen med hans analyse af vareformens indre sammenhæng med tankeformer. Tesen er, at denne sammenhæng hindrer teoriproduktionen og dermed realanalysen af den nuværende reaktionære genkomst. Imidlertid drager Sohn-Rethel ikke konsekvensen af sine analyser - og hans hovedværk Håndens og åndens arbejde er således blevet kritiseret for

2 Cf. Teksterne i Faschismus und Kapitalismus. Theorien über die sozialen Ursprünge in die Funktion des Faschismus.

3 Der fandt en relativt omfattende reception sted af Sohn-Rethels arbejde i Danmark i 1970'erne. For en oversigt, se Carsten Thaus efterskrift til Håndens og åndens arbejde, s. 251-300. hverken at tænke de marxske begreber om abstrakt arbejde eller arbejdets subsumptionsformer ind i erkendelseskritikken, og for at hans revolutionsteori derfor ender med at bekræfte udviklingen af produktionskræfterne. ${ }^{4}$ Artiklens anden del forsøger derfor at supplere Sohn-Rethels arbejde med nyere Sohn-Rethel-inspirerede læsninger af Marx. Ifølge de forskellige værdikritiske strømninger, baseret på genlæsninger af Marx, der primært fandt sted i løbet af 1970'erne, er oplysningsfilosofiens transcendentale tanke- og subjektivitetsformer forbundet med vold, og nazismens udryddelse af de europæiske jøder var intimt forbundet med værdiens abstraktion. ${ }^{5}$ Mange af tidens værdikritiske strømninger er teorihistorisk betragtet stort set uden forbindelse med hinanden, og det er et af artiklens ærinder at sammenligne og forbinde dem med Sohn-Rethels analyse af kapitalforholdets påvirkning af tankeformer og den dermed forbundne genkomst af reaktionære politiske former.

\section{DEL I - OM SOHN-RETHELS FASCISME-ANALYSE}

I Sohn-Rethels udlægning stødte driftsøkonomien sammen med dannelsen af stormonopoler i løbet af 1920'erne; de store foretagender var tvunget til at producere på fuld kapacitet, selvom efterspørgslen manglede. Overproduktion blev et middel til at tvinge sig ud af, men samtidig også forlænge og uddybe akkumulationskrisen. Økonomien blev således spaltet mellem produktionsøkonomiens faste omkostninger og markedsøkonomiens efterspørgsel og prisbevægelser (Sohn-Rethel, Erkendelseskritik 33). Markedets 'usynlige hånd' forsvandt, og økonomien blev 'irrationel', da værdiloven ikke længere var bestemmende for produktionsprocessen. Ifølge Sohn-Rethel var den tyske kapital tvunget til at producere ikke-reproduktive værdier og ikke-konsumerbare produkter, altså "produkter der hverken indgår direkte eller indirekte i opretholdelsen af den menneskelige arbejdskraft eller de materielle produktionsmidler" (Sohn-Rethel

4 Jf. Marx. Grundsrids til kritikken af den politiske økonomi, s. 24. Og beskrivelsen af den formelle og reelle subsumtion af arbejdet i Resultater af den umiddelbare produktionsproces, s. 91-121.

5 Se Kurz og Postone. 
Økonomi og Klassekamp 38; Sohn-Rethel, Håndens 96-7). Oprustning og siden krig blev løsningen for den tyske kapital. Kun sådan var det muligt at opfylde produktionsformålet.

I afsnittet om "Reproduktive eller ikke-reproduktive værdier" i Håndens og åndens arbejde, foreslår han, at spaltningen mellem driftsøkonomi og markedsøkonomi er et tegn på den kapitalistiske produktionsmådes bankerot. Men, "da den sociale revolution, som skulle gøre en ende på den, imidlertid udeblev" (her er der tale om erfaringerne fra opstandene i Tyskland i perioden 1919-1923), var der ikke andet at gøre end at "videreføre den kapitalistiske produktion uafhængigt af markedet, dvs. at lade den producere ikke-markedsgængse produkter efter rent bedriftsøkonomiske nødvendigheder". Produktionen af ikke-reproduktive værdier og en udpresning af den absolutte merværdi er "den økonomiske definition på fascisme" ifølge Sohn-Rethel. Produktionen af ikke-reproduktive værdier tenderer mere til at ødelægge end til at reproducere det samfundsmæssige liv (Sohn-Rethel, Håndens 163).

Baggrunden for omlægningen til en fascistisk økonomi ligger derfor i kapitalismens besvær med at reproducere sig selv, hvorfor fascismen er en kontrarevolutionær løsning på en krise i den kapitalistiske økonomi. ${ }^{6}$ I Tyskland var fascismens udvikling betinget af modsætninger i den kapitalistiske økonomi, som åbenbarede sig i overgangen fra driftsøkonomien til dannelsen af de store monopoler. Die Vereinigten Stahlwerke AG, stiftet i 1926, er ifølge Sohn-Rethel det mest oplagte eksempel på denne tendens. Jane Caplan understreger i sit efterord til den engelske udgave, The Economy and Class Structure of German Fascism, at Sohn-Rethels fascismeanalyse netop er udledt af spørgsmålet om kapitalens værdiøgningsproces (Sohn-Rethel, The Economy 164). Sohn-Rethels tese er nemlig, at overgangen til en fascistisk kapitalkommando var kendetegnet ved omlægning til den absolutte merværdiproduktion sikret af en statslig voldsmetode. Denne måtte så "ødelægge den hidtidige og til den relative merværdiproduktion hørende massebasis" for bourgeoisiets herredømme: "først og fremmest

6 I Trumps kontrarevolution læser Mikkel Bolt genkomsten af fascisme i USA og Vesten som en håndtering af den krise, de avancerede økonomier har været i siden begyndelsen af 1970'erne.
79 JAMES DAY

DEN SPALTEDE AFFORTRYLLELSE

fagforeningerne og socialdemokratiet, samtidig med proletariatets politiske selvorganisering, og erstatte den med en anden, nemlig den nationalsocialistiske massebasis" (Sohn-Rethel, Håndens, 75).

Produktionen af den absolutte merværdi består som bekendt i, "at arbejdsdagen forlænges ud over det punkt, hvor arbejderen har produceret en ækvivalent for værdien af sin arbejdskraft", hvorimod den relative merværdi er en effektivisering af værdiskabelsen, via f.eks. "gennemgribende omvæltning af de tekniske arbejdsprocesser og grupperinger i samfundet" (Marx, Kapitalen 724). Den tyske industrifascismes "øverste princip" var således "den faste begrænsning af arbejdsomkostningernes totalbeløb". En af de mest øjnefaldende metoder til at øge produktion af den absolutte merværdi var opslugningen af seks millioner arbejdsløse, som skulle dele nettoindkomstsummen med de tolv millioner arbejdere, der allerede var beskæftigede. Dog syntes oprustningsøkonomien kun at uddybe de problemer, industrifascismen skulle løse. Bourgeoisiet blev klemt, da deres egen interesse i at ophæve det fascistiske diktatur var i konflikt med "dets klasseinteressers profit- og tabsregning". Som Sohn-Rethel formulerede det: "jo mere af bourgeoisiets porcelæn, der går i stykker, desto bedre går det for partiet" (Sohn-Rethel, Håndens 76).

Helt overordnet: omlægningen til fascisme er en foregøglet kontrarevolutionær løsning på kriser inden for kapitalismen, som skal knuse arbejdernes organisationer med henblik på at kunne gennemtvinge omfattende omstruktureringer, der imidlertid kun radikaliserer de modsigelser, de var oprettet for at løse. Fascismen fremstår således som en immanent udviklingsmulighed inden for nationalstatens demokratier med kapitalismen som den herskende produktionsmodus. Fascismen er derfor ikke en undtagelse, der står i opposition til national-demokratiet, men tværtimod en mulighed inden for demokratiet, der kan udvikle sig for at bevare den kapitalistiske produktionsmåde. For Sohn-Rethel var den fascistiske ideologi netop kendetegnet ved en antikapitalistisk appel på kapitalistisk grundlag. Det vil sige, at den trak veksler på en antikapitalistisk retorik og antisemitisk udryddelsespolitik, mens den bevarede den kapitalistiske produktionsmåde. 
80 KULTUR \& KLASSE $* 126 * 2018$ DET REAKTIONÆRE

REALABSTRAKTION OG DEN NØDVENDIGE FALSKE BEVIDSTHED Sohn-Rethels teoretiske hovedpræstation er en materialistisk erkendelseskritik, der påviser tankeformers indre sammenhæng med vareformens beskaffenhed, som beskrevet af Marx i det første bind af Kapitalen. I Hånden og åndens arbejde afviser Sohn-Rethel en oplysningstendens, hvor arbejdere i stadigt højere grad bliver bevidst om deres rolle i produktionsprocessen. Han argumenterer i stedet for, at bevidstheden under vareabstraktionens dominans adskilles fra erkendelsen. Her har fremmedgørelsen ikke noget med bevidstheden at gøre. Den følger snarere af samfundsmæssige udvekslinger, der sædvanligvis foregår bag ryggen på transaktionernes aktører. Penges funktion som almenækvivalent, er, ifølge Sohn-Rethel, afgørende for tankeformer: "enhver der har en mønt i lommen", skriver han, "må have ganske bestemte begrebslige abstraktioner i hovedet, om han så er bevidst om det eller ej" (Sohn-Rethel, Håndens 86). Hovedtesen i Håndens og åndens arbejde er, at det kun er i kraft af udvekslinger medieret af penge, at den rene forstand, altså en form for abstrakt tænkning med forankring i det transcendentale subjekt, kan overkomme dens umiddelbare omstændigheder og produktionsprocesser. Sohn-Rethel danner begrebet "realabstraktion", for at sammenfatte vareabstraktionens homologi med tankeformer. I indledningen, skriver han således, at eftersom

mennesket først en gang er blevet udstyret med dette samfundsmæssige produkt, som 'den rene forstand' jo er, finder det sig selv spaltet i et uvæsen, der med sit intellekt yder universelt åndeligt arbejde og med sin krop individuelt håndarbejde, og hvor sammenhængen mellem de to former for arbejde er absolut umulig at få øje på. (Sohn-Rethel, Håndens 22)

Det menneskelige væsen er blevet revet itu af vareformens inhærente tvedeling af kvalitet og kvantitet, og pengeformens funktion som almenækvivalent har muliggjort, at abstrakt tænkning er afskåret fra den fysiske produktion. I Sohn-Rethels teori er det netop en spaltning i den marxske teori, som skal løses ved at koble kritikken af den politiske økonomi sammen med en kritik af erkendelsesteorien (25). Indtil det sker, vil samtlige varebesiddere lide af det, Sohn-Rethel kalder "den nødvendige falske bevidsthed" (219-224). "Den private varebesidders forstands lys", skriver han, "vil aldrig kunne hæve den samfundsmæssige værens formørkelse, lige så lidt som
81 JAMES DAY

DEN SPALTEDE AFFORTRYLLELSE

de lommelygter, vi forvirrede os rundt med under krigen" (102). Men da revolutionen udebliver, har vi ikke desto mindre kun det enkelte spotlys at dingle rundt med i det samfundsmæssige mørke. Da bevidstheden nødvendigvis er falsk, er det kun igennem ændringer i de samfundsmæssige udvekslinger, at en form for forsoning mellem inhærente iturivende tankeformer kan finde sted. Udfordringen for en marxistisk videnskab om den reaktionære politik er således ikke kun besværliggjort af udelukkelsen fra kapitalklassens små kredse, men i endnu højere grad af måden, hvorpå kapitalismens udvikling ødelægger erkendelsen. Roealabstraktionen river tankeformerne itu.

\section{DEL II - TIL EN KRITIK AF ANTIFASCISME OG FOR EN IKKE-IDENTIFICERENDE KAPITALKRITIK}

Analysen af reaktionens aktuelle genkomst kan med fordel bygge videre på Sohn-Rethels forslag om at kombinere kritikken af den politiske økonomi med erkendelseskritik. Analysen af det reaktionæres genkomst må med andre ord til en vis grad formidles gennem en materialistisk kritik af erkendelsesteorien. I afsnittet om værdibegrebet, som synes at være lig med vareabstraktionen i Sohn-Rethels udlægning, slår han fast, at realabstraktionen kan lokaliseres i cirkulationssfæren, og at den altså ikke har en inhærent sammenhæng med arbejdet, "vareabstraktion er en bytteabstraktion, ikke en arbejdsabstraktion", hedder det i Håndens og åndens arbejde (73). Realabstraktionen er netop afledt af overgangen fra en samfundsmæssig syntese betinget af produktionsforhold til en syntese præget af udvekslingsforhold. Den erstatter, i stedet for at supplere, en kritik af det abstrakte arbejde. Det er netop her, Sohn-Rethel er blevet kritiseret i de nye Marx-læsninger, der blev igangsat nogenlunde samtidig med udgivelsen af Håndens og andens arbejde. Via en rekonstruktion af Marxs økonomikritiske tekster var det muligt for de nye Marx-læsninger at videreudvikle forståelsen af den marxske værdi- og kapitalopfattelse (Rosdolsky; Reichelt). Sohn-Rethels realabstraktionsbegreb kan med fordel forankres i disse analyser.

Mens Sohn-Rethel forsøger at bevise nødvendigheden af at forbinde kritikken af den politiske økonomi med en materialistisk erkendelses- 
teoretisk kritik, så er han i mindre grad opmærksom på den historiske overgang til en fuldkommen subsumtion af livet under kapitalen og de konsekvenser, det har for politisk organisering og revolutionsteorien. Hans revolutionsteori er kort sagt fuldstændigt utilstrækkelig i forhold til hans erkendelseskritik. For Sohn-Rethel er det klasseløse samfund opnåeligt via en samfundsmæssig syntese i kraft af produktionsprocessen. Det medfører en vis rådvildhed i forestillingerne om en kommende revolution og tilrettelæggelse af et kommunistisk samfund. Hans argument er således at det ved overgangen til en fuldkommen samfundsmæssiggørelse af arbejdet, opnået via taylorismens rationalisering af produktionsprocessen, netop er muligt at ændre produktionsforholdene "på basis af den nuværende udvikling af de materielle produktivkræfter" (Sohn-Rethel, Håndens 177). Så snart produktionsprocessen når et stadie, hvor samtlige produktionsprocesser er samfundsmæssiggjort, er det ifølge Sohn-Rethel muligt at skimte kapitalklassens overflødighed og dermed også arbejdernes overtagelse af produktionsprocessen, som Sohn-Rethel desværre gør lig med det kommunistiske samfund. Sohn-Rethels fremskridtsoptimisme tager slet ikke højde for den erkendelseskritik, han selv har udviklet. Negationen af kapitalismen er nødvendigvis langt mere omfattende og skal omfatte såvel produktionsprocessen som værdiformen.

For så at kunne videreudvikle Sohn-Rethels teori vil det være nødvendigt hinsides analysen af den samfundsmæssige syntese, der sker når penge bliver en almenækvivalent, at præcisere, hvordan arbejdskraftens omslag til vareform samt udviklingen af arbejdets subsumtionsformer under kapitalen er konstituerende for en afspaltning af tankeformerne, der går dybt ned i det transcendentale subjekt.

Det er netop Sohn-Rethels interesse for tankeformer på bekostning af tankens indhold, som den danske kapitallogiker Hans-Jørgen Schanz kritiser i en af ekskurserne i Til rekonstruktionen af kritikken af den politiske økonomis omfangslogiske status, udgivet i 1973, tre år efter Håndens og åndens arbejde (Schanz 126-131). Ifølge Schanz har Sohn-Rethel misforstået kapitalens udviklingslogik, da han hypostaserer bytteaktens realabstraktion som "synthesislogik" (129). I stedet for at forsøge at begribe kapitalbevægelsens modsætninger i dens bevægelse, fokuserer Sohn-Rethel uheldigvis kun på
83 JAMES DAY

DEN SPALTEDE AFFORTRYLLELSE

et enkelt moment. Mest overraskende er det for Schanz, at Sohn-Rethel ikke er i stand til at gennemtænke arbejdets subsumptionsformer i kapitalismens udvikling, men blot analyserer en ahistorisk abstraktionsform gennem en begrænset udlægning af vareformens udvikling, der ikke er i stand til at tage højde for processernes modsætninger, som ifølge Schanz udgør det kapitalistiske samfunds synteseformer (129).

Ligesom Schanz er den værditeoretiske strømning inden for marxismen - som Sohn-Rethel er et vigtigt forbillede for - kritisk indstillet over for Sohn-Rethels fokus på cirkulationssfæren. Begrebet realabstraktion kan nemlig kun opstå på grundlag af en afvigelse fra Marxs forståelse af abstrakt arbejde (Jappe, "Sohn-Rethel" 7). Det forsimplende fokus på cirkulation forklarer Sohn-Rethels blindhed over for en udvidet fremmedgørelse forårsaget af arbejdets mere og mere omfattende subsumtion under kapitalen. Ifølge værditeoretikeren Moishe Postone analyserer Sohn-Rethel "ikke arbejdets særstatus i kapitalismen som værende socialt konstruerende, men snarere som to former for sociale synteser" (Postone Time 177). Postone understreger, at Sohn-Rethels teori ikke er i stand til at analysere tankeformens forhold til de sociale forhold, de opstår i, netop fordi han overser arbejdets rolle i den samfundsmæssige syntese. For Postone er den samfundsmæssige syntese heller ikke formgivet af arbejdet som sådan, men fra formen af sociale relationer i hvilket produktionen finder sted (178). Schanz', Postones, og Jappes kritikpunkter peger på nødvendigheden af at sætte Sohn-Rethels omfattende erkendelsesteoretiske projekt i dialog med nyere værdikritiske læsninger af Marx. I den forbindelse kunne man yderligere fremhæve f.eks. Chris Arthur, Robert Kurz og Roswitha Scholz, for blot at nævne nogle af de mest indflydelsesrige, men det er en opgave, der kun kort kan berøres her. Selvom det ikke er muligt at præcisere, hvordan Sohn-Rethel kan forbindes med de forskellige værdikritiske analyser, er det dog muligt at skimte muligheden for en antifascisme-kritisk kapitalkritik.

Sohn-Rethels udsagn om et spaltet erkendelsesgrundlag kan med fordel relateres til den reelle subsumtion af arbejdet. Arbejdskraften er nu blevet reduceret til en vare, som er med til at afsondre håndens og åndens arbejde fra hindanden, med den bivirkning, at erkendelsesgrundlaget er 
brudt itu. ${ }^{7}$ Når arbejdskraften er blevet til en vare, indgår den netop i det samme kredsløb som andre varer, således at cirkulations- og produktionssfæren synes at smelte sammen. Produktionen er således blevet en del af kapitalbevægelsens varecirkulerende produktionsproces, som har revet sig løs fra den enkelte kapitals kontrol. Ved arbejdets reelle subsumtion under kapitalen, hvor arbejdsprocessen er bestemt af produktionen af den relative merværdi (Marx, Resultater 97), bliver arbejdskraften som vare efterhånden også produceret ligesom alle andre varer, altså som en integreret del af den kapitalistiske produktionsmodus. Børnepasning, rengøring, madlavning osv. bliver alt sammen medieret via kapitalforholdet. Det er selvfølgelig vigtigt at understrege, at der er to abstraktionsprocesser på færde, når det drejer sig om penge og arbejdskraft. Penge synes at være en ren abstraktion i kapitalismen, altså en vare uden brugsværdi og legemliggørelsen af den ellers udelukkende abstrakte bytteværdi, men det er også en realabstraktion, der er bestemmende for tankeformerne. Derimod er det abstrakte arbejde netop ikke en givet arbejdsproces, $\mathrm{fx}$ skomageri, men den indholdsløse regning af en ombyttelig arbejdstid- og kraft, der er med til at producere enhver vare (Marx, Kapitalen 155). I den engelske værditeoretiker Chris Arthurs formulering, er "penge som det alment ækvivalente for værdiformen [...] afgørende for værdiens virkelighed og, på indirekte vis, en forudsætning for abstrakt arbejde" (113). På trods af hans interesse for rationalisering af arbejdsprocesserne er Sohn-Rethel imidlertid ikke i stand til at redegøre for, hvordan ændringer i arbejdets subsumtionsformer præger de samfundsmæssige udvekslinger, medieret af penge, der er så afgørende for hans kritik af erkendelsesteorien.

Moishe Postones forsøg på at analysere national-socialismens antisemitiske udryddelseslogik på basis af værdiabstraktionen er et afgørende bidrag til forsøget på at udvide Sohn-Rethels erkendelseskritik i en historisk retning, da det forbinder værdikritik med en analyse af fascismen. Postone slår fast, at koncentrationslejrene var afgørende for national-socialismens antikapitalistiske appel, fordi nazisterne identificerede jøderne med kapi-

7 Der er forskellige opfattelse af, hvorvidt arbejdets subsumtionsformer kan bruges som periodiserende termer. F.eks. Theorie Communiste bruger det som sådan. I nærværende sammenhæng er det dog tænkt som en logisk, og ikke historisk udvikling.
85 JAMES DAY

DEN SPALTEDE AFFORTRYLLELSE

talismens værdiabstraktioner (Postone, Deutschland 144). Udryddelse af jøderne vil således kunne forstås som et horribelt forsøg på at komme kapitalismens herskende abstraktioner til livs. Nazismens antisemitisme, hvor kapitalens abstraktionsproces forsøges lokaliseret $\mathrm{i}$ konkrete mennesker, viser nødvendigheden af at kortlægge kapitalismens værdiøgningsprocesser og de relationer, de skaber.

I Økonomi og klassekamp skriver Sohn-Rethel, at en analyse af fascismens udvikling, ikke kan "baseres på beretninger om personer", men snarere på deres "økonomiske karaktermaske", hvis de forstås som personifikationer af de økonomiske relationer (25). Det giver mere mening at analysere de økonomiske relationer, der er med til at tvinge nationale demokratier over i fascistiske diktaturer. Derfor skal en antifascistisk politik hele tiden også indeholde en kritik af kapitalismens værdiøgningsbevægelse og dens kriser. Dannelsen af en antifascistisk enhedsfront synes derfor ikke at være en mulighed, da en sådan ikke tager sigte på de mere grundlæggende modsigelser i det kapitalistiske nationaldemokrati og derfor tenderer til at bevare de kapitalinteresser, der medvirkede i omslaget til fascismen. I stedet for at analysere fascismens forudsætninger, den måde den ligger som en skjult mulighed inden for ethvert nationaldemokrati med en kapitalistisk produktionsmåde, fokuserer antifascismen på bekæmpelsen af den fascistisk fare specifikt. Dermed tenderer den til at være med til at bevare - og anspore til deltagelse i - de politisk og $ø$ konomiske organisationsmåder som burde kritiseres. Det var netop det, som den italienske kommunist Amadeo Bordiga advarede imod allerede i 1920'erne. I stedet for kun at bekæmpe den fascistiske fare som en uforklarlig exces er det opgaven at forsøge at analysere - $\mathrm{i}$ forlængelse af blandt andre Sohn-Rethel, Postone og de nyere værdikritiske strømninger, der udbygger på disses kritiske projekt - hvordan nationaldemokrati, fascisme og kapitalisme hænger sammen, historisk og aktuelt.

JAMES DAY. Postdoc. Billedkunstskolernes afdeling for teori og formidling,Det kongelige danske kunstakademi. Har publiceret artikler om samtidskunst og krise i tidsskrifter som Nordic Journal of Aesthetics og Rethinking Marxism. 
86 KULTUR \& KLASSE $* 126 * 2018$

DET REAKTIONÆRE
87 JAMES DAY

DEN SPALTEDE AFFORTRYLLELSE

\section{FRACTURED DISENCHANTMENT}

Linking Alfred Sohn-Rethel's analysis of fascism with his critique of epistemology, 'Fractured Disenchantment' makes the case for a preliminary theoretical study for the analysis of the return of reaction, primarily, in the case of this article, within Europe and the US. In the 1930s, Sohn-Rethel was in the privileged position of having access to the inner-workings of the German capitalist class at the same time as being part of communist resistance to the rise fascism. In Manual and Intellectual Labour, parts of which were derived from his attempt to come to terms with his experience of fascism, Sohn-Rethel published the results of decades of work on a materialist critique of epistemology in 1970. By tracing some of the links between Sohn-Rethel's theory and critical responses to it in the new readings of Marx taking place at the same period, this article tries to link the critique of value with a critique of anti-fascism, arguing for a non-identificatory critique of capital as the basis for an analysis of reactionary politics today.

\section{KEYWORDS}

DA: Alfred Sohn-Rethel; epistemologikritik; antifascisme; værdikritik

EN: Alfred Sohn-Rethel; critique of epistemology; anti-fascism; critique of value

\section{LITTERATUR}

Abendroth, Wolfgang, Kurt Kliem, Jörg Kammler og Rüdiger Griepenburg. Faschismus und Kapitalismus - Theorien über die sozialen Ursprünge in die Funktion des Faschismus.

Wien: Europäische Verlagsanstalt: Frankfurt og Europa Verlag, 1967.

Adorno, Theodor W. og Alfred Sohn-Rethel . Briefwechsel 1936-1969. Herausgegeben von Christoph Gödde. München: edition text + kritik, 1991.

Arthur, Christopher J. "Value and Money". Marx's Theory of Money - Modern Appraisals. Red. Fred Moseley. Basingstoke: Palgrave Macmillan, 2005. 111-123.

Bolt, Mikkel. Trumps kontrarevolution. København: Nemo, 2017.

Jappe, Anselm. "Sohn-Rethel and the Origin of 'Real Abstraction': A Critique of Production or a Critique of Circulation?". Historical Materialism 211 (2013): 3-14.

Jappe, Anselm. "Towards a History of the Critique of Value". Capitalism, Nature, Socialism 252 (2014): 25-37.

Marx, Karl. Kapitalen. København: Rhodos, 1971.

Marx, Karl. Resultater af den umiddelbare produktionsproces. Aarhus: Modtryk, 1974.

Marx, Karl. Grundrids til kritikken af den politiske økonomi. Aarhus: Modtryk, 1974.
Postone, Moishe. Time, Labor and Social Domination: A Reinterpretation of Marx's Critical Theory. New York and Cambridge: Cambridge University Press, 1993.

Postone, Moishe. Deutschland, die Linke und der Holocaust. Freiburg: ça ira, 2005.

Reichelt, Helmut. Zur logischen Struktur des Kapitalbegriffs bei Karl Marx. Europäische Verlagsanstalt: Wien: Frankfurt og Europa Verlag, 1970.

Rosdolsky, Roman. Zur Enstehungsgeschichte des Marxschen <Kapital>. Frankfurt: Europäische Verlagsanstalt, 1968.

Schanz, Hans-Jørgen. Til rekonstruktionen af kritikken af den politiske økonomis omfangslogiske status. Aarhus: Modtryk, 1973.

Sohn-Rethel, Alfred. Håndens og Åndens Arbejde. København: Rhodos, 1975.

Sohn-Rethel, Alfred. Erkendelseskritk og klassekamp - Et bidrag til kontrovers omkring Alfred Sohn-Rethel. København: Rhodos, 1976.

Sohn-Rethel, Alfred. Økonomi og klassekamp i den tyske fascisme. Kongerslev og Grenå: GMT, 1975.

Sohn-Rethel, Alfred. The Economy and Class Structure of German Fascism, oversat Martin Sohn-Rethel, med et efterord af Jane Caplan. London: Free Association Books, 1987.

Sohn Rethel, Alfred. "Das Ideal des Kaputten Über Neapolitanische Technik". Frankfurter Zeitung 21. marts 1926 Erstes Morgenblatt.

Sohn-Rethel, Alfred. Warenform und Denkform - Aufsätze. Frankfurt am Main: Europäische Verlagsanstalt og Wien: Frankfurt og Europa Verlag, 1971.

Sohn-Rethel, Alfred. Die ökonomische Doppelnatur des Spätkapitalismus. Luchterhand Darmstadt og Neuwied, 1972.

Sohn-Rethel, Alfred. Von der Analysis des Wirtschaftens zur Theorie der Volkswirtschaft Methodologische Untersuching mit besonderem Bezug auf die Theorie Schumpeters. Emsdetten: Verlagsenstalt Heinr \& J. Lechte, 1936.

Sohn-Rethel, Alfred. Soziologische Theorie der Erkenntnis. Frankfurt am Main: Suhrkamp, 1985

Toscano, Albert. "The Open Secret of Real Abstraction". Rethinking Marxism. 202 (2008): 273-287.

Von Braunmuhl, Claudia. "Economy and Class Structure in German Fascism". Capital and Class 42 (1980): 144-147. 
88 KULTUR \& KLASSE * $126 * 2018$ DET REAKTIONÆRE 